\title{
A Closer Look into Primary School Students' Self- efficacy in L2 Learning across Gender and School Location
}

\author{
Syafi'ul Anam \\ English Department \\ Universitas Negeri Surabaya \\ Surabaya, Indonesia \\ syafiul.anam@unesa.ac.id
}

\author{
Susanto \\ English Department \\ Universitas Negeri Surabaya \\ Surabaya, Indonesia \\ susanto@unesa.ac.id
}

\begin{abstract}
Self-efficacy is believed to drive learners to have a greater cognitive and motivational engagement in learning activities, and accordingly help them to perform better. This study, therefore, aimed to look into the profile of students' selfefficacy levels across school location and gender. The data of the study were collected from 522 six graders enrolled in twelve primary school in East Java through a self-reported questionnaire. The data were then analysed using multivariate analyses of variance. The results revealed that girls were more confident in English and self-regulatory abilities than boys. Moreover, urban primary school students had a firmer belief in performing language tasks than their suburban and rural peers; and suburban students held a stronger conviction in their English skill than their rural peers. Urban and suburban students had a greater confidence in their self-regulatory skills in English learning than their rural peers. The study underlines the environmental factor of learners' self-efficacy, thereby helping teachers better understand their students' affect.
\end{abstract}

Keywords-self-efficacy; L2 learning; primary school; school location; gender

\section{INTRODUCTION}

Self-efficacy belief is a major motivational process in learning engagements. The self-belief drives learners to be more resilient and persistent when dealing with difficult tasks [1],[2] and more motivationally and cognitively engaged in learning processes [3]. Learners with firm self-efficacy are more likely to gain better learning results [4], [5], [6], [7] and better at regulating their own learning [8], [9], [10], [11]. The learners who are confident with their ability also tend envision successes and to be more task-focused and less worried with possible failures [12], [6].

Despite its crucial roles revealed mainly from research domains other than foreign/second (L2), self-efficacy has yet to be researched adequately in L2 field [13], [14]. Unfortunately, some of the few L2 studies [15], [16] employed 'pseudo-selfefficacy scales' [17]: p. 288] that might gauge other selfcontructs [17], thereby undermining the validity of the findings. Additionally, although self-efficacy is rooted in Bandura's [2],[18] triadic reciprocality model — the interlink between personal factors (i.e. cognition and belief), behaviors and enviroment, the role of learners' environment has so far been overlooked in self-efficacy research across domains, let alone in L2 area. Therefore, this study examined the possible influence of gender and school location, which might be reflective of enviromental and personal factors, on young learners' self-efficacy belief in order to provide more information about young learners' self-efficacy.

\section{LITERATURE REVIEW}

\section{A. Self-efficacy belief}

Self-efficacy is individuals' subjective judgement of their own ability to organize and complete specific tasks [18]. This definition features two principal points: focus on perceived abilities to perform specific tasks; and, context specificity [17], [19]. Thus, self-efficacy varies by level, generality, and strength [18]. For example, learners have high self -efficacy in retelling a story in the classroom but low self-efficacy in presenting a research paper in a conference. Self-efficacy, which is context-specific, should be distinguished from selfconfidence in which the latter refers to a stable trait that involves perceived L2 competence and language anxiety [20], [21]. Besides, self-efficacy is mainly influenced by observation of others' success or failure, task completion, and social persuasion [2] while self-confidence is affected by the quantity and quality of interactions with the native speakers of the target language [22].

Self-efficacy is a major agency mechanism in that it affects the way individuals think and behave, especially in difficult situations [23]. In academic contexts, self-efficacy can induce learners' motivational, cognitive, and behavioural engagements in instructional activities [3]. That is why learners who believe in their ability tend to be more involved in learning processes and try harder to do given tasks. The learners are likely to be more resilient and persistent when encountering difficult tasks and adverse learning situations, and they take such tasks and situations as challenges [24]. The high self-efficacious learners with high self-efficacy are also more task-centered, mastery oriented, envision successes, while their low self-efficacy counterparts are worried about failures and tend to avoid doing tasks [12]. Self-efficacy is also crucial in self-regulated learning. With the self-belief, learners are more motivated in self-regulatory process, such as planning, monitoring, and evaluating one's own cognition [26]. The self-belief provides learners with 'staying power', which allows them to use their 
skills and strategies persistently in spite of obstacles or distractions [25]. For these reasons, Pajares [26] argued that learners' achievement arguably not only depends their skills, but also their belief that they can apply the skills.

\section{B. Role of self-efficacy in L2 learning}

Research primarily undertaken with university and adolescent learners have showed that learners who are confident with their L2 ability are likely to have better listening and reading proficiency [27], writing achievement [28],[14], and L2 achievement in general [4], [29], [30], [31], [32]. Learners with believe in their ability were more capable of selfregulating their learning [5] and demostrated greater interest, positive attitude and effort [14]. In addition, learners with high self-efficacy regardless of their achievement levels attributed their failure to causes within their control, such as lack of effort, which is useful in nurturing underachieved learners' belief in their ability to achieve better.

Like L2 self-efficacy, the conviction to self-manage one's learning, the so-called self-regulated learning efficacy, plays a crucial role in language learning. Empirical evidence from studies in the fields other than L2 has indicated that it is significantly related to academic success [25], [6], metacognive strategies [33], and motivational beliefs, such as self-concept, goal orientation, and apprehension [6].

\section{Self-efficacy, gender, and learning context}

Learning contexts and gender also contribute to selfefficacy level. Studies [6], [25], [34] have revealed that learners' self-efficacy in self-regulation went down as they progressed through their schooling. The decline could be because of increasing complexity and demand of academic tasks the learned had to work on.

Research on gender differences in self-efficacy across academic domains have reported inconsistent findings. Boys were more confident in their math abilitis than girls [26], [35], but girls reported higher sense of self-efficacy in language arts than boys [36]. In a study with French studentst, Mills et al. [31] indicated that girls possessed stonger belief in their selfregulatory skills in language learnig than boys. This might suggest what Onwuegbuzie et al. [37]: p.12] called as a "female oriented foreign language culture", in which learning a foreign langauge is perceived as more suitable for girls than men.

To conclude, despite its pivotal role, self-efficacy in L2 learning for young learners has still remained underexplored, let alone on its link with environmental factors. Therefore, the study sought to examine whether gender and school location, indicative of environmental factors, affected the Indonesian young learners' self-efficacy for English and for self-regulatory skills. Specifically, the study examined whether 1) female and male students differed in self-efficacy for English and for selfregulatory skills and 2) students who were enrolled in rural, suburban and urban primary school differed in the two types of self-efficacy beliefs.

\section{METHODS}

The participants involved in the study were 522 sixth graders and mostly eleven years old. They came from public primary schools located in an Indonesian province. They consisted of 238 rural students, 203 suburban students, and 81 rural students. The wide gap in student number is caused by the fact that urban schools generally have more students than those in suburban and rural areas. The data were collected using background information questionnaire and Children's selfefficacy for learning English questionnaire (C-SELEQ). The questionnaire consisted of two subscales: (1) English selfefficacy and (2) self-regulated learning efficacy, with 8 and 5 items respectively. The first subscale assessed students' belief in their ability to perform language tasks (listening, speaking, reading, writing); the second subscale measured participants' perception in their self-regulatory ability in learning English. The results of the exploratory factor analysis supported the factor structure of the questionnaire, and the questionnaire also had good internal consistency reliability (Cronbach's alpha values of .860 for the first subscale and .774 for the second one). The data obtained from the questionnaires were then analysed using one-way multivariate analysis of variance (MANOVA) to look into possible differences across gender and school location in the scores of both self-efficacy subscales.

\section{RESULTS AND DISCUSSION}

\section{A. Differences in self-efficacy between boys and girls}

One-way MANOVA was run to identify possible significant differences in the means of English self-efficacy and self-regulated learning efficacy as a function of gender. Preliminary analysis showed that no univariate and multivariate outliers were observed in the two groups of the participants. All the assumptions, like linearity and homogeneity of variance-covariance matrices, were met.

The multivariate test revealed that there was a significant main effect of gender on the combined scores of the two selfefficacy beliefs, $F(2,519)=6.549, p=.002$; Pillai's Trace $=$ .025 , partial $\eta^{2}=.025$. With a Bonferroni adjustment $(\alpha$ level $=$ .025), subsequent ANOVAs indicated that girls were significantly different from boys in English self-efficacy $(F(1$, $520)=10.569 ; p=.001$, partial $\left.\eta^{2}=.02\right)$ and self-regulated learning efficacy $\left(F(1,520)=10.782 ; p=.001\right.$, partial $\eta^{2}=$ $.02)$. The differences mean that girls perceived themselves more capable of doing language tasks and regulating their own learning than boys did.

The results imply that self-efficacy in English is affected by gender. The evidence accords with that of previous observations on gender differences in self-efficacy in language arts [36]; it was found that female students had firmer selfefficacy than boys. In light of triadic reciprocality model, instead of biological factor, environmental and personal (cognitive and behavioral) ones might play apart in the difference [38]. The gender differences quite likely has something to do with attitude towards L2 learning. In Clark and Trafford's [39] investigation, female students were more engaged in L2 tasks, whereas their male counterparts did not 
pay much attention and invested less time. Or, the differences could be simply due to gender-related conceptions [26]; female students are perceived to be better at learning language than male students, and learning language suits the female more [37], [39].

\section{B. Differences in self-efficacy between students across school location}

One-way MANOVA was also used to look into possible significant differences in self-efficacy for English and selfregulated learning between rural students $(\mathrm{n}=81)$, suburban ones $(n=203)$, and urban ones $(n=238)$. Initial analyses showed no outliers in the three groups of participants and the assumptions were also met.

The main effect of school location on the linear combination of the two self-efficacy scores was statistically significant, $F(4,1038)=13.220, p<.0001$; Pillai's Trace $=$ .097 , partial $\eta^{2}=.05$. The effect size indicated that only $5 \%$ of variation in self-efficacy was accounted for by school location, which was small. Subsequently, a series of ANOVAs run to identify any possible significant differences between the three groups of students. Levene's test showed that the assumption of the equality of variance was met $(p>.05)$. Results showed that there were significant differences in self-efficacy for English $(F(2,519)=20.411 ; p<.0001)$ and self-efficacy for self-regulatory skills $(F(2,519)=8.450 ; p<.0001$ between rural, suburban and urban schools. School location had a greater effect on English self-efficacy $\left(\right.$ partial $\left.\eta^{2}=.07\right)$ than on self-regulated learning efficacy (partial $\eta^{2}=.03$ ).

Pairwise analyses were conducted to spot individual significant variations of both self-efficacy scores across the three groups. Results of the mean comparisons revealed that there were significant differences in self-efficacy for English between urban and rural students, between suburban and rural students, and between urban and suburban students $(\mathrm{p}<.05)$. Likewise, self-regulated learning efficacy also varied significantly between students from suburban and rural regions and between those from urban and rural regions $(p<.05)$, but not between those from urban and suburban regions. Such patterns indicate urban students' greater confidence in the ability to complete English task and language learning; and suburban students had stronger belief to do English tasks and self-regulation than their rural peers did.

Such differences are possibly the result of English proficiency and/or environmental support. Therefore, it is reasonable that the rural students were more inferior to urban and suburban students in their English and self-regulatory skills. The role of environmental support in motivational processes, like self-efficacy, confirms Bandura's [2] triadic reciprocality model.

Teachers, classmates, school facilities, private English tuition, and families could become environmental factors affecting students' self-efficacy. In Indonesia, urban or suburban teachers, who generally possess English teaching qualification, are more likely to have better English and pedagogical skills than rural teachers. Specifically, urban teachers might be better at giving positive feedback on their students' tasks or selecting reasonably hard tasks which can be completed with some effort. Urban and suburban students may be superior to their rural peers as they possibly have more peers who have good English. Accordingly, the students have more opportunities to observe their peers manage to perform English tasks successfully; through such observations, they will possibly become more convinced that they can do the tasks well like their peers. Observing others' successful task completions, getting positive feedback, and having prior successful accomplishment are the main factors in developing self-efficacy [2], [35]. In addition, the role of environmental factors was highlighted in Wright's [40] research, revealing the significant effect of classmates, school amenities, and teachers on attitudes towards L2 learning.

\section{CONCLUSION}

School location and gender differences in the Indonesian young learners' beliefs in the competence to do English tasks and to manage their learning in this study confirm the influential role of environmental and cognitive factors to the development of self-efficacy. The findings have implications for teaching practice. Teachers should realize the nature and importance of this motivational process in language learning, and how it can be developed. The teachers should be equipped with the know-how of raising and sustaining their learners' self-efficacy. The teacher should help nurture the self-efficacy of learners who might already believe in their ability and that of learners who doubt it. The first action is to train students in how to evaluate their own ability in L2 learning accurately. The accurate evaluation can help the learners shy away from tasks they thought difficult, although they, in fact, have the ability to deal with it. The teachers also should design teaching activities which can nurture a sense of self-efficacy, like providing reasonably difficult tasks. This is because being successful and seeing others succeed in task completion can raise students' self-efficacy. Another crucial implication is the improvement of English teaching in rural schools through, among others, professional development of their teachers and provision of adequate learning resources.

\section{ACKNOWLEDGMENT}

We would like to thank the participants, school teachers and principals for their help in data collection process.

\section{REFERENCES}

[1] A. Bandura, "Perceived self-efficacy in cognitive development and functioning," Educ. Psychol., vol. 28, pp. 117-148, 1993.

[2] A. Bandura, Self-efficacy: The exercise of control. New York: W. H. Freeman, 1997.

[3] E. A. Linnenbrink and P. R. Pintrich, "The role of self-efficacy beliefs in student engagement and learning in the classroom," Read. Writ. Q. Overcoming Learn. Difficulties, vol. 19, pp. 119-137, 2003.

[4] P. P. H. Hsieh and H. S. Kang, "Attribution and self-efficacy and their interrelationship in the Korean EFL context," Lang. Learn., vol. 60, pp. 606-627, 2010.

[5] F. Y. Tilfarlioglu and F. S. Ciftci, "Supporting self-efficacy and learner autonomy in relation to academic success in EFL classrooms (a case study)," Theory Pract. Lang. Stud., vol. 1, pp. 1284-1294, 2011.

[6] E. L. Usher and F. Pajares, "Self-efficacy for self-regulated learning: A validation study," Educ. Psychol. Meas., vol. 68, pp. 443-463, 2008. 
[7] G. B. Yeo and A. Neal, "An examination of the dynamic relationship between self-efficacy and performance across levels of analysis and levels of specificity," J. Applies Psychol., vol. 91, pp. 1088-1101, 2006.

[8] S. Anam and E. Stracke, "Language learning strategies of Indonesian primary school students: in relation to self-efficacy beliefs," System, vol. 60, pp. 1-10, 2016.

[9] S. Graham, "Learner strategies and self-efficacy: Making the connection," Lang. Learn. J., vol. 35, pp. 81-93, 2007.

[10] A. Mizumoto, "Exploring the effects of self-efficacy on vocabulary learning strategies," Stud. Self-Access Learn. J., vol. 3, pp. 423-437, 2012 .

[11] A. Mizumoto, "Effects of self-regulated vocabulary learning process on self-efficacy," Innov. Lang. Learn. Teach., vol. 7, pp. 253-265, 2013.

[12] I. S. Al-Harthy, C. A. Was, and R. M. Isaacson, "Goals, efficacy and metacognitive self-regulation: A path analysis," Internatiional J. Educ., vol. 2, pp. 1-21, 2010.

[13] D. H. Kim, C. Wang, and H. S. Ahn, "English language learners' selfefficacy profiles and relationship with self-regulated learning strategies," Learn. Individ. Differ., vol. 38, pp. 136-142, 2015.

[14] L. Woodrow, "College English writing affect: Self-efficacy and anxiety," System, vol. 39, pp. 510-522, 2011.

[15] J. M. Magogwe and R. Oliver, "The relationship between language learning strategies, proficiency, age and self-efficacy beliefs: A study of language learners in Botswana," System, vol. 35, pp. 338-352, 2007.

[16] M. Su and P. Duo, "EFL learners' language learning strategy use and perceived self-efficacy,” Eur. J. Soc. Sci., vol. 27, pp. 335-345, 2012.

[17] M. Bong, Asking the right questions: How confident are you that you could successfully perform these tasks? Self-efficacy beliefs of adolescents. Greenwich, CT: Information Age Publishing, 2006.

[18] A. Bandura, Social foundations of thought and action: A socio cognitive theory. New Jersey: Prentice-Hall, Inc., 1986.

[19] A. Bandura, Guide for creating self-efficacy scales Self-efficacy beliefs of adolescents. Greenwich, CT: Information Age Publishing, 2006.

[20] K. A. Noels, G. Pon, and R. Clement, "Language, identity, and adjustment: The role of linguistic self-confidence in the acculturation process," J. Lang. Soc. Psychol., vol. 15, pp. 246-264, 1996.

[21] P. D. MacIntyre, Z. Dörnyei, R. Clement, and K. A. Noels, "Conceptualizing willingness to communicate in a L2: A situational model of L2 confidence and affiliation," Mod. Lang. J., vol. 82, pp. 545-562, 1998.

[22] R. Clement, Z. Dörnyei, and K. A. Noels, "Motivation, self-confidence, and group cohesion in the foreign language classroom," Lang. Learn., vol. 44, pp. 417-448, 1994.

[23] A. Bandura, "Human agency in social cognitive theory," Am. Psychol., vol. 44, pp. 1175-1184, 1989.

[24] M. Komarraju and D. Nadler, "Self-efficacy and academic achievement: Why do implicit beliefs, goals, and effort regulation matter?," Learn. Individ. Differ., vol. 25, pp. 67-72, 2013.
[25] G. V. Caprara et al., "Longitudinal analysis of the role of perceived selfefficacy for self-regulated learning in academic continuance and achievement," J. Educ. Psychol., vol. 100, pp. 525-534, 2008.

[26] F. Pajares, "Gender and perceived self-efficacy in self-regulated learning," Theory Pract., vol. 41, pp. 116-125, 2002.

[27] N. Mills, F. Pajares, and C. Herron, "The reevaluation of the role of anxiety: self-efficacy, anxiety, and their relation to reading and listening proficiency," Foreign Lang. Ann., vol. 39, pp. 276-295, 2006.

[28] M. Rahimpour and R. Nariman-Jahan, "The influence of self-efficacy and proficiency on EFL learners' writing," J. Instr. Technol. Distance Learn., vol. 7, pp. 19-32, 2010.

[29] P. P. H. Hsieh and D. L. Schallert, "Implications from self-efficacy and attribution theories for an understanding of undergraduates' motivation in a foreign language course," Contemp. Educ. Psychol., vol. 33, pp. 513-532, 2008

[30] A. D. Liem, S. Lau, and Y. Nie, "The role of self-efficacy, task value, and achievement goals in predicting learning strategies, task disengagement, peer relationship, and achievement outcome," Contemp. Educ. Psychol., vol. 33, pp. 486-512, 2008.

[31] N. Mills, F. Pajares, and C. Herron, "Self-efficacy of college intermediate French students: Relation to achievement and motivation," Lang. Learn., vol. 57, pp. 417-442, 2007.

[32] F. Y. Tilfarlioglu and E. Cinkara, "Self- efficacy in EFL: Differences among proficiency groups and relationship with success," NovitasROYAL, vol. 3, pp. 129-142, 2009.

[33] Y. J. Joo, M. Bong, and H. J. Choi, "Self-efficacy for self-regulated learning, academic self-efficacy, and internet self-efficacy in web-based instruction," Educ. Technol. Res. Dev., vol. 48, pp. 5-17, 2000.

[34] F. Pajares and G. Valiante, "Students' self-efficacy in their selfregulated learning strategies: A developmental perspective," Psychol. An Int. J. Psychol. Orient, vol. 45, no. 2, pp. 211-221, 2002.

[35] G. Joët, E. L. Usher, and P. Bressoux, "Sources of self-efficacy: An investigation of elementary school students in France," J. Educ. Psychol., vol. 103, pp. 649-663, 2011.

[36] F. Pajares and G. Valiante, Handbook of writing research Self-efficacy beliefs and motivation in writing. New York: Guilford Press, 2006.

[37] A. J. Onwuegbuzie, P. Bailey, and C. E. Daley, "Cognitive, affective, personality, and demographic predictors of foreign language achievement," J. Educ. Res., vol. 94, pp. 3-15, 2001.

[38] K. Bussey and A. Bandura, "Social cognitive theory of gender development and differentiation," Psychol. Rev., vol. 106, pp. 676-713, 1999.

[39] A. Clark and J. Trafford, "Boys into Modern Languages: An investigation of the discrepancy in attitudes and performance between boys and girls in modern languages," Gend. Educ., vol. 7, pp. 315-326, 1995

[40] M. Wright, "Influences on learner attitudes towards foreign language and culture," Educ. Res., vol. 41, pp. 197-208, 1999. 